\title{
ASSESSMENT OF DIVERSITY OF PHENOLOGICALLY AND MORPHOLOGICALLY RELATED TRAITS AMONG ADAPTED POPULATIONS OF SUNFLOWER (Helianthus annuus L.)
}

\author{
Sahari Khoufi ${ }^{1^{*}}$, Khalil Khamassi ${ }^{1}$, Jaime A. Teixeira da Silva ${ }^{2}$, \\ Nadia Aoun ${ }^{1}$, Salah Rezgui ${ }^{1}$, Fayçal Ben Jeddi ${ }^{1}$ \\ ${ }^{1}$ Unité Cultures Maraîchères et Florales, Institut National Agronomique \\ de Tunisie, 43, avenue Charles Nicolle 1082 Tunis-Mahrajène Tunisie, \\ Université de Carthage, Tunisia \\ ${ }_{2}^{2}$ P. O. Box 7, Miki-cho post office, Ikenobe 3011-2, Kagawa-ken, 761-0799, Japan
}

Received: September 10, 2012 Accepted: June 10, 2013

SUMMARY

Drought and heat stress that prevail during critical growth stages are amongst the most important constraints controlling yield ability of a sunflower crop. In this investigation, 73 adapted lines were evaluated under irrigated and rainy conditions using 7 checks for 100-seed weight (HSW), seed crude protein (SCP), kernel-grain ratio (KGR), hull-kernel ratio (HKR), leaf area (LA), total leaf area (TLA), stem height (SH), leaf number (LN), stem diameter (SD), seed width (SW), seed length (SL), head diameter (HD), leaf length (LL), leaf width (LW), leaf length-leaf width ratio (LLW), number of days of the cycle (NDC), and GDD (growing degree day), GDD (Emergence - Flowering) (GDD E-F), GDD (Flowering - Maturity) (GDD F-M), and GDD (Emergence - Maturity) GDD (EM). There were significant differences $(P<0.001)$ between genotypes for all traits while a positive correlation between them ranged from 0.40 to 0.95 . Principal component analysis indicated that two principal components accounted for $51.26 \%$ of total variability. The two axes were defined primarily by HSW, LL, LA, SW, SL, LN, SD, and GDD. Three groups were identified. The first group characterized by the highest HSW, SL, SW, SD and the second group characterized by the least LA. Sunflowers with low GDD constituted the third group. To determine a similarity index between different lines, we constructed a dendrogram generated by hierarchical UPGMA. Cluster analysis of the similarity coefficient matrices revealed five major clusters having 90\% similarity. The selection of a genotype from this sunflower diversity would be an alternative to generate genetic material for breeding programs and yield improvement in semi-arid conditions.

Keywords: sunflower, drought, diversity, growth degree day, Tunisia, biological cycle

* Corresponding authors: Sahari Khoufi, e-mail: sk111183@yahoo.fr; Jaime A. Teixeira da Silva, e-mail: jaimetex@yahoo.com 


\section{INTRODUCTION}

Sunflower (Helianthus annuus L.) is a summer crop belonging to the Asteraceae family, and is used in Tunisia for its seeds as "dry fruit" (glibettes), oil crop, and cattle feed using seed meal. Sunflowers may also be useful in the cosmetic industry and for other purposes, including a source of biofuel (Ballerini 2006). Despite its multiple uses, this crop is still not well expanded in Tunisia, covering a small area mainly in the northwest of Tunisia with $80 \%$ of the sown area lying within the Bèja governate DGPA (2008). The average cropping area ranges from $10,000-12,000$ ha per year. Tunisia, as many other sunflower-growing countries (France, Italy, Cordoba, etc.) has a Mediterranean climate characterized by a pattern that combines early in the season, low temperatures with water availability but later on, the higher temperatures coincide with a lack of water (Flagella et al. 2002; Soriano et al. 2004). The flowering stage and period of sunflowers spans from June to July, and this period is considered to be the most sensitive to water shortage in which water becomes exceedingly scarce in Tunisia. Thus, the Mediterranean climate and the nature of the vegetative cycle of sunflowers are among the factors that limit its expansion.

This problem is compounded by the type of soil, which is isohumic, with a dominantly coarse texture and a poor polyhedral structure in central and centereast of Tunisia unlike the Marley calcareous zone with a fine texture and a well developed polyhedral structure in the northern zone of Tunisia (Mtimet 2000).

To overcome Mediterranean environments, many studies have suggested agricultural practices such as early sowing and irrigation to deal with environmental constraints caused by water scarcity (Agüera et al. 1997; Casadebaig et al. 2008). In this study, we have characterized morphological and phenological variation in 75 accessions of adapted sunflower and seven hybrids evaluated in an upper semi-arid site of Tunisia, namely Tunis. Through this characterization we aim to determine the diversity within this collection and select genotypes that may resist water shortage as assessed by their morphological and phenological traits. These accessions were sampled from five populations collected from three regions (Bèja, Bizerte and Jendouba). We also discuss distinctive morphological and phenological traits that may be considered to be selective criteria in a selection program dealing with hydric stress.

\section{MATERIAL AND METHODS}

The experiment was carried out at the National Institute of Agronomy of Tunisia (INAT) on a $112 \mathrm{~m}^{2}$ plot with the following geographic coordinates $\left(10^{\circ} 11^{\prime} \mathrm{E}\right.$ long., $36^{\circ} 49^{\prime} \mathrm{N}$ lat., $38 \mathrm{~m}$ above sea level). The type of soil was alluvial, with a silty and clay texture, and a relatively high $\mathrm{pH}$ (8.03), containing $2.12-2.55 \%$ organic matter. The bioclimatic site in INAT is semi-arid characterized by a mild winter, a wet and windy 
spring, and a dry summer. The water supply was evaluated to $67 \%$ of optimum hydric needs of sunflowers i.e., $550 \mathrm{~mm}$.

Table 1: The sunflowers collection composed by lines and hybrids collected from three different regions

\begin{tabular}{|c|c|c|c|c|c|c|c|c|c|c|}
\hline \multicolumn{11}{|c|}{ Lines' codes } \\
\hline 1 & C18.1.3.2 & 16 & C10.2.3.2 & 31 & C26.1.1.2_II & $47 \mathrm{C} 18.2 .1 .3$ & 62 & C11.3.2.2 & 77 & C25.2.3.1 \\
\hline 2 & C14.2.1.2 & 17 & C3.2.3.2 & 32 & C9.1.2.2 & $48 \mathrm{C} 12.2 .3 .2$ & 63 & C6.3.2.2 & 78 & C19.2.3.3 \\
\hline 3 & C3.2.1.2 & 18 & C31.3.2.3 & 33 & C33.111II55BR & 49 C7.3.1.2 & 64 & C2.2.2.1 & 80 & C31.1.1.2 \\
\hline 4 & C34.2.3.3 & 19 & C39.2.3.2 & 34 & C18.2.2.1 & 51 C11.1.2.2 & 65 & C24.2.3.2 & \multicolumn{2}{|r|}{ Hybrids' codes } \\
\hline 5 & C1.3.2.2 & 20 & C1.3.1.1 & 35 & C28.2.1.2 & 52 C4.3.1.2 & 66 & C9.1.1.1 & 29 & XF4564_X051 \\
\hline 7 & C4.1.1.2 & 21 & C26.2.3.1 & 36 & C21.1.1.2 & $53 \quad C 4.2 .3 .1$ & 67 & C4.2.1.2 & 37 & PR63A04_X51 \\
\hline 8 & C4.2.2.1 & 22 & C10.2.1.2 & 38 & C12.2.2.2 & $54 \mathrm{C} 11.2 .2 .2$ & 68 & C41.2.3.2 & 44 & 64A71_X051 \\
\hline 9 & C10.1.1.2 & 23 & C1.2.2.3 & 39 & C1111_III61A1 & 55 C20.2.2.2 & 69 & C29.1.1.2 & 73 & 64A89_X051 \\
\hline 10 & C1.3.3.2 & 24 & C10.3.1.2 & 40 & C18.2.3.3 & $56 \quad$ C2.3.3.1 & 70 & C15.2.3.2 & 79 & 64A71TUNISIA09 \\
\hline 11 & C2.3.1.2 & 25 & C5.1.2.2 & 41 & C13.1.3.2 & 57 C28.2.3.1 & 71 & C6.2.1.3 & 6 & 63D82-X051 \\
\hline 12 & C7.3.2.2 & 26 & C7.2.1.1 & 42 & C1.1.2.2 & 58 C27.2.3.2 & 72 & C9.2.3.1 & 50 & 63D82TUNISIA09 \\
\hline 13 & C5.2.3.2 & 27 & C45.2.3.2 & 43 & C37.2.3.1 & 59 C16.2.2.1 & 74 & C44.2.3.2 & & \\
\hline 14 & C25.2.2.1 & 28 & C15.2.2.2 & 45 & C8.3.1.2 & $60 \mathrm{C} 21.2 .3 .3$ & & C23.2.3.1 & & \\
\hline 15 & C13.3.1.1 & 30 & C5.2.1.2 & 46 & C46.2.3.2 & $61 \quad C 14.2 .3 .2$ & 76 & C1.2.1.2 & & \\
\hline
\end{tabular}

The different genotypes (Table 1) were sown along $2 \mathrm{~m}$-long rows spaced $70 \mathrm{~cm}$ apart and a within-row distance of $10 \mathrm{~cm}$. Seeds were inserted $2 \mathrm{~cm}$ deep. Plants were thinned when each plant had three pairs of leaves, maintaining a density of 8 plants per row. Nineteen morphological and phenological descriptions were evaluated at various growth stages using a standard evaluation system for sunflower (Schneiter et al. 1998) and the terminology recommended by the International Union for the Protection of New Varieties of plants UPOV (2000). Table 2 describes the different characters and the appropriate measurements made in each growth stage.

Table 2: Traits related to morphology, phenology and seeds with their measurement's growth stage as recommended by the International Union for the Protection of New Varieties of Plants

\begin{tabular}{|c|c|c|}
\hline \multicolumn{2}{|c|}{ Traits } & \multirow{2}{*}{$\begin{array}{c}\text { Stage of measurement } \\
\text { Flowering (F3.2) }\end{array}$} \\
\hline $\begin{array}{l}\text { Leaf length }(\mathrm{LL})(\mathrm{cm}) \text {, } \\
\text { leaf width }(\mathrm{LW})(\mathrm{cm}) \text {, } \\
\text { leaf length/leaf width }(\mathrm{LLW}) \text {, } \\
\text { leaf area }(\mathrm{LA})\left(\mathrm{cm}^{2}\right) \text {, }\end{array}$ & $\begin{array}{l}\text { total leaf area }(T L A)\left(\mathrm{cm}^{2}\right) \text {, } \\
\text { stem height }(\mathrm{SH})(\mathrm{m}), \\
\text { leaf number }(\mathrm{LN})\end{array}$ & \\
\hline $\begin{array}{l}\text { Head diameter }(\mathrm{HD})(\mathrm{cm}), \\
\text { stem diameter }(\mathrm{SD})(\mathrm{cm}), \\
100-\text { seed weight }(\mathrm{HSW})(\mathrm{g}), \\
\text { seed crude protein }(\mathrm{SCP})(\%),\end{array}$ & $\begin{array}{l}\text { kernel-grain ratio (KGR), } \\
\text { hull-kernel ratio }(\mathrm{HKR}) \text {, } \\
\text { seed length }(\mathrm{SL})(\mathrm{mm}) \text {, } \\
\text { seed width }(\mathrm{SW})(\mathrm{mm})\end{array}$ & Maturity (M0), (M4) \\
\hline \multicolumn{2}{|c|}{ Number of days of the cycle (NDC) } & Emergence (A) - maturity (M4) \\
\hline \multicolumn{2}{|c|}{ GDD Emergence - Flowering (GDD E-F) $\left({ }^{\circ} \mathrm{C}\right)$} & Emergence $(\mathrm{A})$ - Flowering (F3.2) \\
\hline \multicolumn{2}{|c|}{ GDD Flowering - Maturity (GDD F-M) $\left({ }^{\circ} \mathrm{C}\right)$} & Flowering (F3.2) - Maturity (M4) \\
\hline \multicolumn{2}{|c|}{ GDD Emergence - Maturity (GDD E-M) $\left({ }^{\circ} \mathrm{C}\right)$} & Emergence $(\mathrm{A})$ - maturity (M4) \\
\hline
\end{tabular}


All traits were analyzed by SAS (version 9.0, Institute Inc., Cary, NC, USA) using Fisher's protected LSD test (i.e., F-test) at $P<0.05$ (Beaux et al., 1991). Analysis of variance (ANOVA) was calculated according to a general linear model while principal component analysis (PCA) was used to assess the consistency of the 19 plant traits. Using PCA scores, it was possible to generate a dendrogram on the basis of UPGMA (Unweighted Pair Group Method with Arithmetic Averages) analysis and generate a similarity percentage. The consistency of plant traits was assessed by examining correlations between different traits.

\section{RESULTS AND DISCUSSION}

ANOVA showed significant variation among the different genotypes $(P<0.05)$ for all traits: HSW, SCP, KGR, HKR, LA, TLA, SH, LN, SD, SW, SL, HD, LL, LW, LLW, NDC, GDD E-F, GDD F-M, and GDD E-M. Despite uniform environmental conditions, genotypes presented significant diversity, as was also observed for Clarkia unguiculata populations (Jonas and Geber 1999). Differences in GDD (E-M) between accessions suggest that the development of a sunflower group may be possible. To develop such a group, we conducted PCA.

Table 3: Values and proportions of three principal components

\begin{tabular}{ccccc}
\hline & Eigenvalue & Difference & Proportion & Cumulative \\
\hline 1 & 6.96 & 4.18 & $36.64 \%$ & $36.64 \%$ \\
2 & 2.77 & 0.70 & $14.61 \%$ & $51.26 \%$ \\
3 & 2.07 & & $10.92 \%$ & $62.18 \%$ \\
\hline
\end{tabular}

PCA analysis (Table 3 ) explained $62.18 \%$ of total variation in the local collection. The first PCA axis explained $36.64 \%$ of total variability related mostly to LL, LW, LA, TLA, HD and GDD (E-M). The second PCA axis explained $14.61 \%$, characterized by HSW, LN, GDD (E-F), SL and SW. The third axis explained $10.92 \%$ of this variability related mainly to GDD (F-M). Although there was significant variation between all traits, the PCs were mainly related to yield-related traits (HSW, SL, SW), leaf traits (LA, TLA, LL, LW, LN) and phenological traits (GDD). These parameters could suffice as parameters for data collection in further studies and possibly as selective criteria to overcome abiotic stress. In fact, PCA showed three groups (Figure 1). Although $67 \%$ of optimum water requirement of sunflowers was used in our experiment, the first group (GI) is characterized by the highest HSW (10.59 g), SL and SW $(13.25 ; 8.22)$ and stem diameter $(28.09 \mathrm{~mm})$ Thus, considering HSW, SL and SW, genotypes belonging to GI had the greatest (i.e., relative to groups II and III (GII and GIII)) potential for crop productivity. GII, representing hybrids, is characterized by low LA $\left(314.27 \mathrm{~cm}^{2}\right)$. This characteristic makes transpiration limited under deficit hydric conditions (Blanchet and Merrien 1990), which may explain the low weight and size of seeds in comparison with GI characterized by the highest LA $\left(564.43 \mathrm{~cm}^{2}\right)$. 


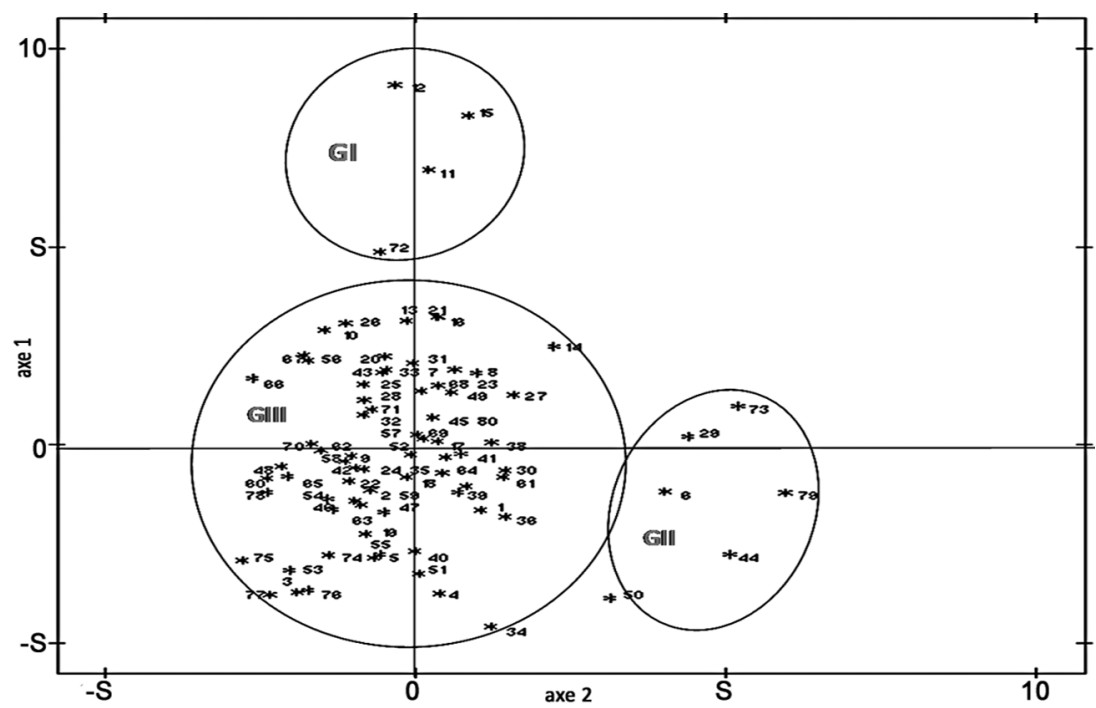

Figure 1: Distribution of the 80 sunflowers accessions for the morphological and phenological traits in the plan of axes 1 and 2. The figure shows three groups, group I (GI), group II (GII), group III (G III).

GIII is defined by the lowest GDD (E-F) $\left(643.11^{\circ} \mathrm{C}\right)$. Hence, genotypes belonging to this group had the most potential for avoiding hydric stress. In fact, GDD accumulation can be used to determine when a crop will flower or mature and can help growers understand how daily warmth provided by the sun and plant growth are related (Cross et al. 1972; Russelle et al. 1984; McMaster and Wilhelm 1997). GDD also helps researchers to develop a chart of the different growth stages of any crop to estimate the adequate sowing and harvest dates. In this study, GDD (E-F) may be considered interesting and distinct among all the other traits. As shown by PCA, GI was characterized by a GDD (E-F) of $657.27^{\circ} \mathrm{C}$, GII had a GDD (E-F) of $695.31^{\circ} \mathrm{C}$ and GIII had the lowest GDD (E-F) $\left(643.11^{\circ} \mathrm{C}\right)$. Thus, this trait may be used to selected genotypes that may be tolerant to abiotic hydric stress. Canavar and Kaynak (2010) considered GDD to be an essential trait when dealing with abiotic stress since breeders look for the lowest GDD that may result in a rapid flowering period avoiding the stress period which normally occurs at the flowering stage under Mediterranean conditions. In fact, Canavar and Kaynak (2010) examined the GDD and sunshine radiation necessary for peanut (Arachis hypogaea L.) maturity. Both parameters were studied during different stages of peanut growth to determine the effects of different planting dates, the most suitable planting dates minimizing climatic stress and achieving maximum yield. Hence, component breeding among selected genotypes based on multivariate analysis would be advantageous in developing ideal sunflower genotypes. Maruthi Sankar et al. (1999a, 1999b, 2001, 2004); Chatfield et al. 1980 confirmed that PCA and regression analysis are interesting for selecting superior sunflower genotypes. A high positive correlation (Table 5 ) ( $r$ varying between 0.40 and 0.95 ) was found between different criteria, HSW was 
significantly correlated with LL, LA, HD, SD and SW. LL was significantly correlated with LW, LA, TLA, SH, HD, SD. Similarly, LW with LA, TLA, SH, HD, and SD; LA with TLA, SH, HD, and SD; TLA with SH, LN, HD, SD, and (GDD E-M); SH with SD, SD, (GDD E-M), and (GDD F-M); LN with HD and (GDD E-F); HD with SD, (GDD EM), and (GDD F-M); SD with (GDD E-M), (GDD F-M), and KGR; SL with SW; (GDD E-M) with (GDD E-F). Maruthi Sankar et al. (2004) also showed significant correlations between diverse quantitative criteria such as LA, LN, HD, SH and other traits related to stem weight, stem nitrogen, total biomass and root weight and length with the coefficient of variation varying between 0.328 and 0.802 . This shows that various traits may result in better and precise selection. In fact, in a breeding program, the choice of correlated components traits should be taken into consideration for selecting genetically diverse parents. From the ANOVA, all traits showed significant variation among accessions. Nevertheless, unlike other traits, SD, HKR, KGR, SCP did not contribute significantly to PCA. To make grouping more accurate and precise, we conducted a cluster based on similarity distances between the genotypes using the same traits.

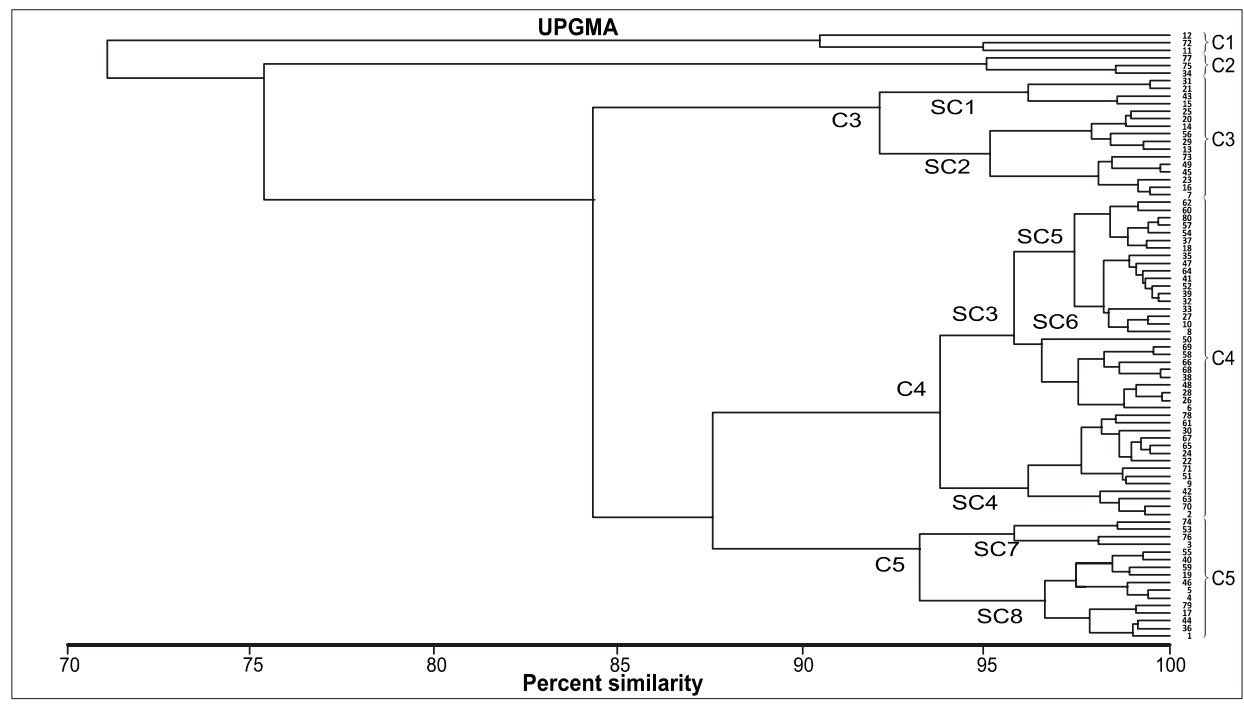

Figure 2: Dendrogram of 80 lines of sunflowers derived by UPGMA from the similarity matrix of the standardized morphological and phenological traits.

Cluster = C; Subcluster = SC. C1 (12, 72,11), C2 (77,75,34), C3 (SC1+SC2), C4 (SC3 (SC5+SC6)+SC4), C5 (SC7+SC8), SC1 (31,21,43,15), SC2 (25, 20, 14, 56, $29,13,73,49,45,23,16,7)$, SC5 $(62,60,80,57,54,37,18,35,47,64,41,52$, $39,32,33,27,10,8)$, SC6 (50, 69, 58, 66, 68, 38, 48, 28, 26, 6), SC4 (78, 61, 30, $67,65,24,22,71,51,9,42,63,70,2), \operatorname{SC7}(74,53,76,3), \operatorname{SC} 8(55,40,59,19$, $46,5,4,79,17,44,36,1)$.

According to cluster analysis (Figure 2), which was based on morphological and phenological traits, 5 major and 8 minor clusters $(C)$ were formed when the cut-off point in the dendrogram was set at the $90 \%$ similarity coefficient. 


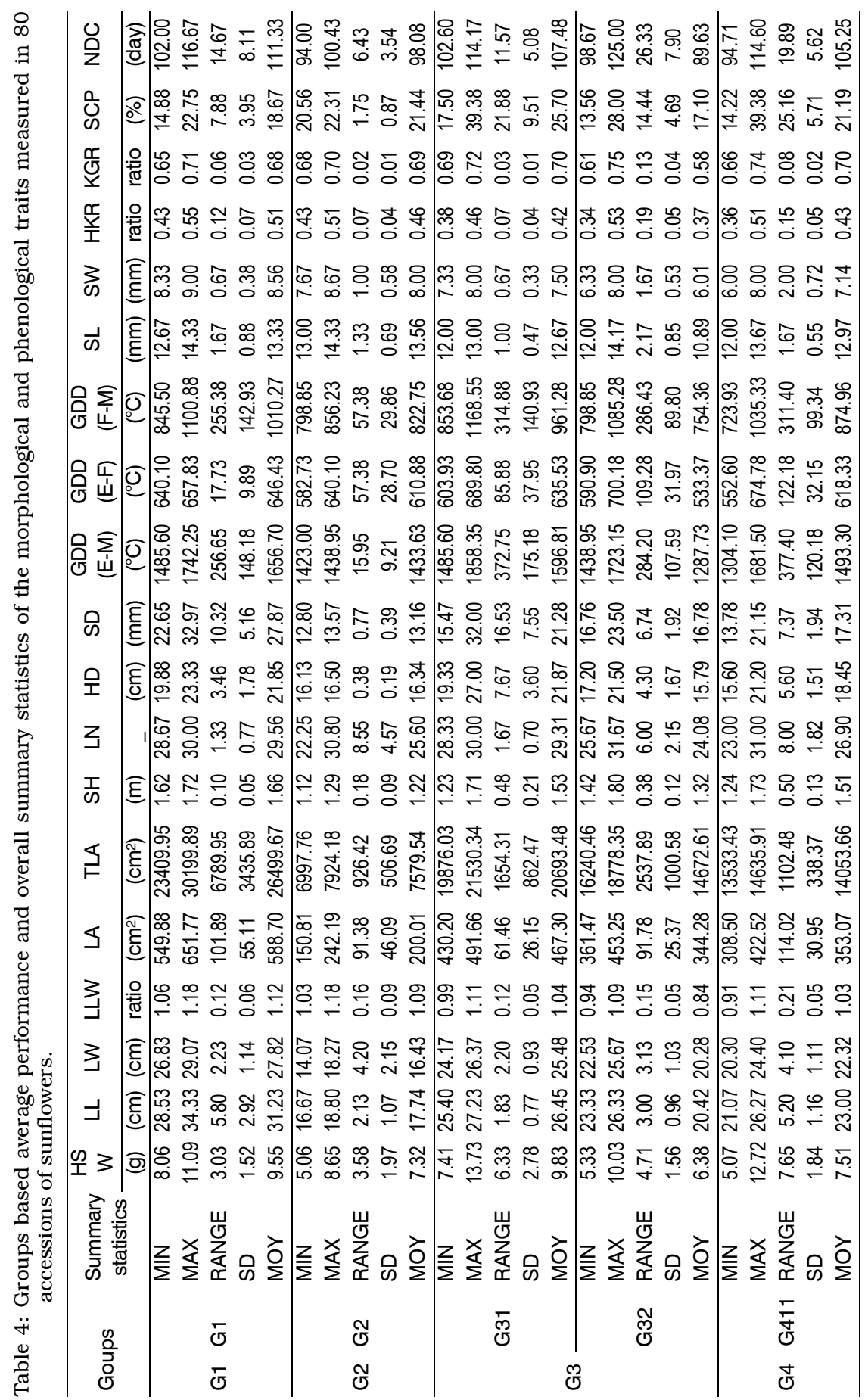




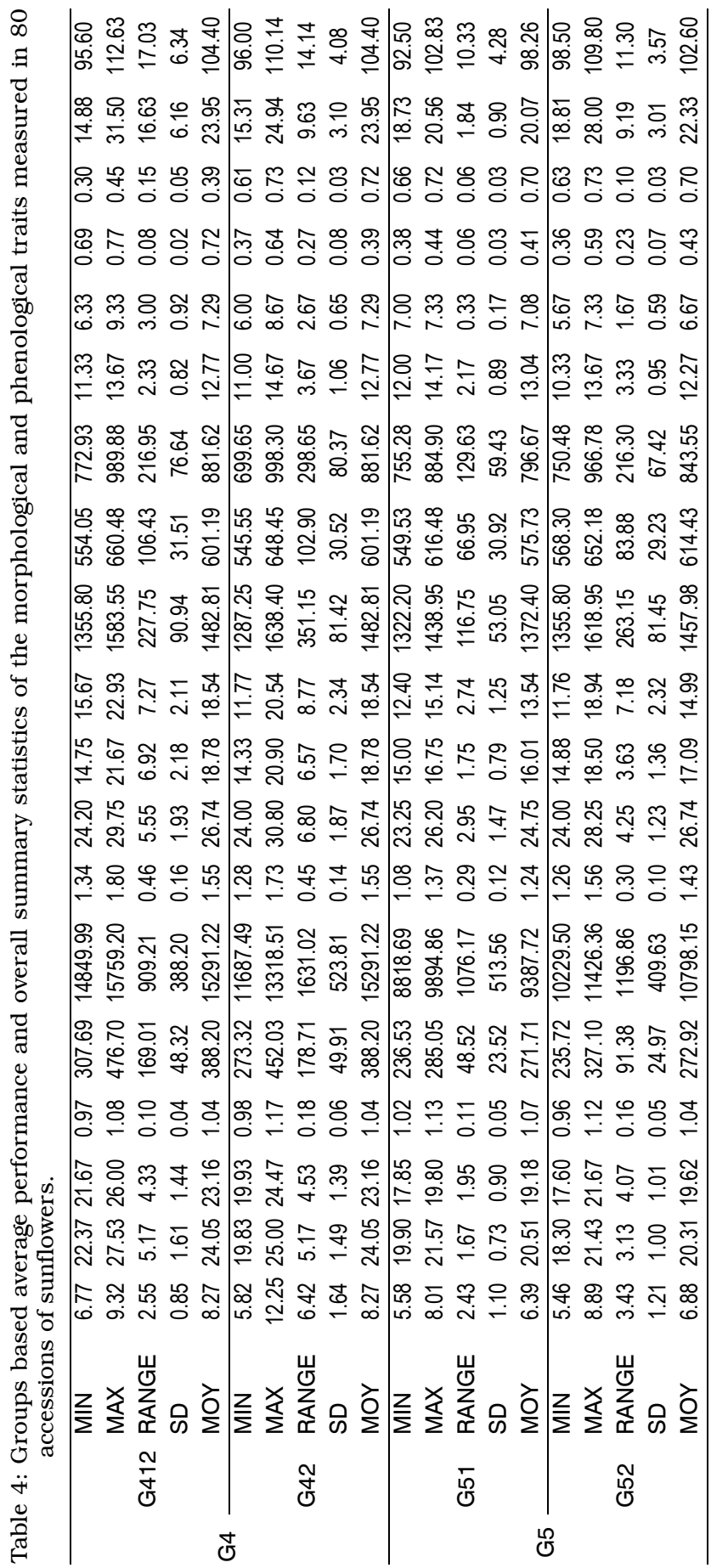

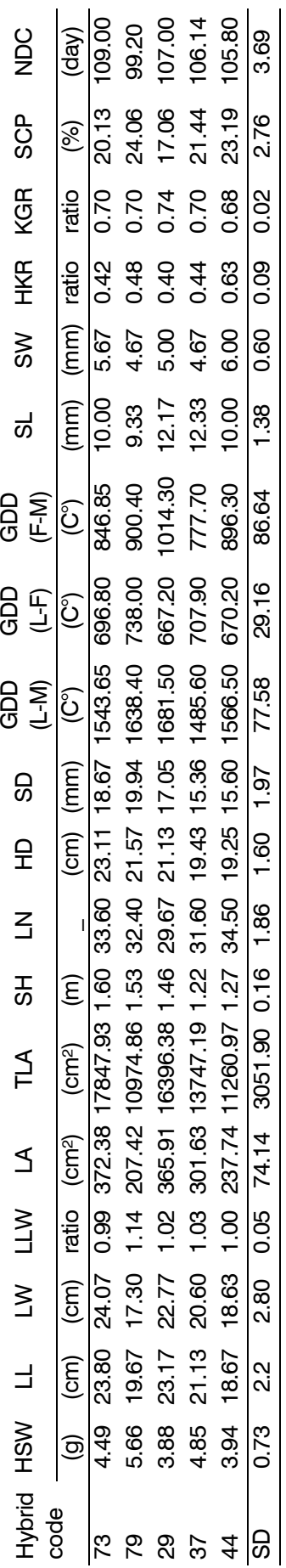




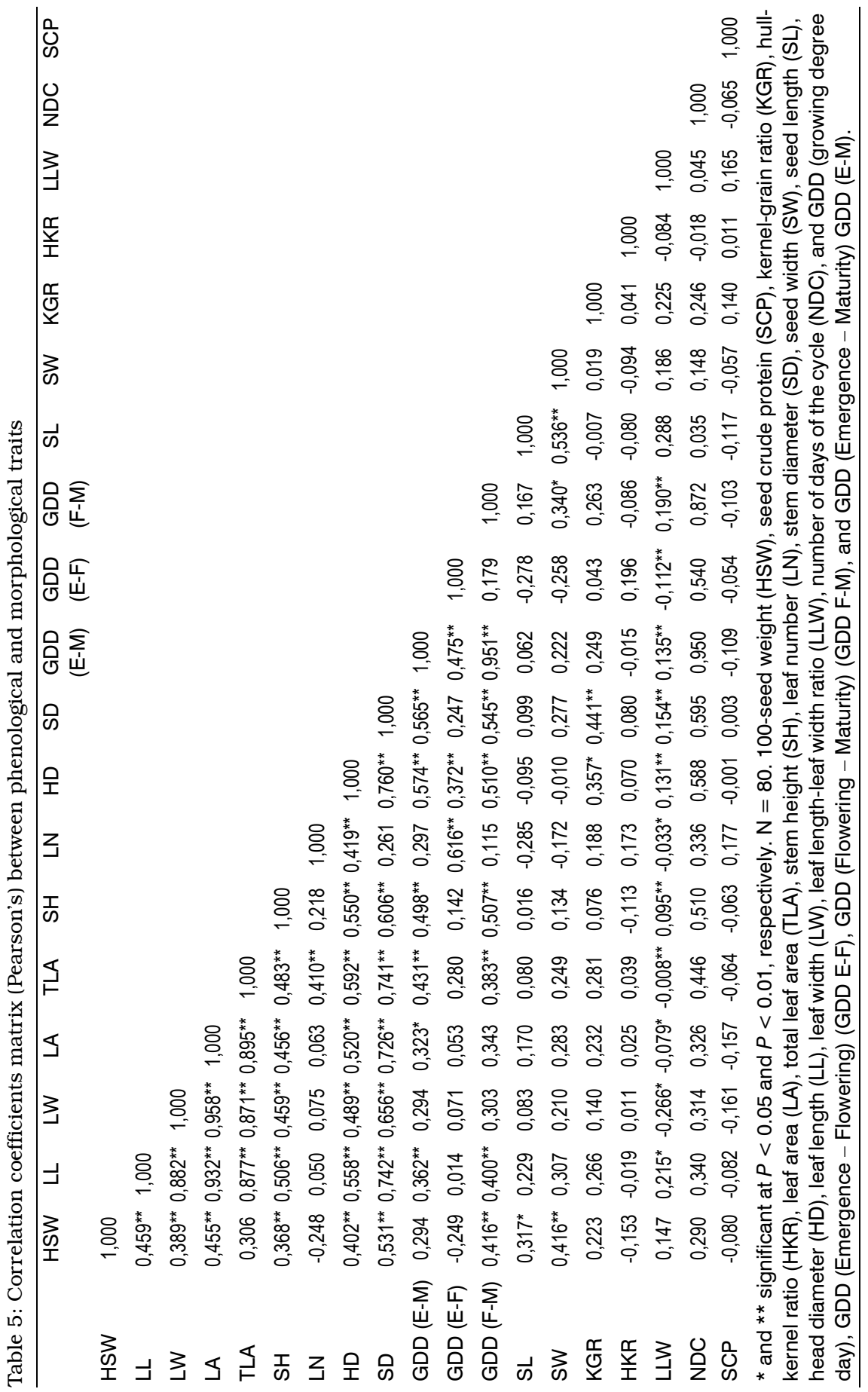


Cluster 4 (C4), was the largest, major cluster divided into four minor subclusters (SC3 (SC5+SC6) + C4) and consisted of 44 lines. C1 and C2 were the smallest, each composed of three lines. $\mathrm{C} 1$ is characterized by the highest average for all morphological and phenological traits, except for SCP, which had the lowest average. GI and C1 could be clearly distinguished by PCA and clustering analysis in Figure 1 and Figure 2, respectively, so much so that genotypes 11, 12 and 72 were common in both analyses. C2 combined genotypes with the least average for all traits. C3, C4 and C5 represent intermediate averages for all traits (Table 4).

\section{CONCLUSION}

This study combined morphological and phenological analyses to determine diversity and variation of 73 adapted sunflowers and 7 hybrids. Variance analysis, PCA and clustering showed morphological and phenological variation between the different lines. Thus, selection according to the methodology described in this study is useful since genotypes with a short developmental cycle related to the least GDD as well as genotypes with least leaf area and genotypes with most potential for crop productivity in water-limited environments could be discovered. However, the use of molecular markers for determining diversity patterns would be of benefit to assess the same germplasm collection and to confirm if the clustering holds true.

\section{ABBREVIATIONS}

- GDD = Growth degree day;

- PCA = Principal Component Analysis;

- $\mathrm{CAR}=$ Character;

- UPOV = International Union for the Protection of New Varieties of Plants

\section{REFERENCES}

Agüera, F., Villalobos, F.J., and Orgaz, F., 1997. Evaluation of sunflower (Helianthus annuus L.) genotypes differing in early vigour using a simulation model. European Journal of Agronomy 7: 109-118.

Ballereni, D., 2006. Les biocarburants état des lieux, perspectives et enjeux du développement, Technip Ginoux, Paris, France, pp. 1-348.

Beaux, M.F., Gouet, H., Gouet, J.P., Morghem, P., Philippeau, G., Tranchefort, J., and Verneau, M. 1991. Logiciel STATITCF. (Impri. ITCF. France. (I.T.C.F. = Institut Technique des Céréales et des Fourrages). 190 p.

Blanchet, R., and Merrien, A., 1990. Le tournesol et l'eau, Points Science, Cetiom, pp. 1- 137.

Canavar, Ö., and Kaynak, M. A., 2010. Growing degree day and sunshine radiation effects on peanut pod yield and growth. African Journal of Biotechnology 9: 2234-2241.

Casadebaig, P., Debaeke, P., and Lecoeur, J., 2008. Thresholds for leaf expansion and transpiration response to soil water deficit in a range of sunflower genotypes. European Journal of Agronomy 28: 646-654.

Chatfield, C., and Collins, A.J., 1980. Introduction to Multivariate Analysis, Chapman and Hall, New York, USA, pp. 382-423.

Cross, H. Z., and Zuber, M. S., 1972. Prediction of flowering dates in maize based on different methods of estimating thermal units. Agronomy Journal 64: 351-355. 
DGPA, 2008. Rapport annuel de suivi des emblavures, Direction des grandes cultures, Direction générale de la production Agricole. Ministère de l'agriculture, de l'environnement et des ressources hydrauliques.

Flagella, Z., Rotunno, T., Tarantino, E., Di Caterina, R., and De Caro, A., 2002. Changes in seed yield and oil fatty acid composition of high oleic sunflower (Helianthus annuus L.) hybrids in relation to the sowing date and the water regime. European Journal of Agronomy 17: 221-230.

Jonas, C.S., and Geber, M.A., 1999. Variation among populations of Clarkia unguiculata (Onagraceae) along altitudinal and altitudinal gradients. American Journal of Botany 86: 333-343.

Maruthi Sankar, G.R., Narasimha Murthy, D., Vanaja, M., and Raghuram Reddy, P., 1999a. A multiple selection index for selecting sunflower genotypes using principal component analysis. Indian Journal of Dryland Agricultural Research and Development 14: 93-103.

Maruthi Sankar, G.R., Vanaja, M. and Raghuram Reddy, P., 2001. Selection of superior genotypes of sunflower using regression analysis. Helia 24(34): 49-62.

Maruthi Sankar, G.R., Vanaja, M. and Raghuram Reddy, P., 1999b. On assessing superiority of sunflower genotypes using principal component analysis. Indian Journal of Applied Statistics 5: 41-53.

Maruthi Sankar, G.R., Vanaja, M., Maruthi, V., Raghuram Reddy, P., and Narasimha Murthy, D., 2004. Selection of consistent plant traits for sunflower growth using principal component analysis. Helia 27(41), 113-122.

McMaster, G. S., and Wilhelm, W. W., 1997. Growing degree-days: one equation, two interpretations. Agricultural and Forest Meteorology 87: 291-300.

Mtimet, A., 2000. Soils of Tunisia. Options Méditerranéennes, Série B 34, pages

Russelle, M.P., Wilhelm, W.W., Olson, R.A., and Power, J.F. 1984. Growth analysis based on degree days. Crop Science 24: 28-32.

Schneiter, A.A., and Miller, J.F., 1998. Description of sunflower growth stages. Crop Science 21: 901-903.

Soriano, M., Orgaz, F., Villalobos, F.J., and Fereres, E., 2004. Efficiency of water use of early plantings of sunflower. European Journal of Agronomy 21: 465-476.

Union Internationale Pour La Protection Des Obtentions Végétales (UPOV) Principes directeurs pour la conduite de l'examen des caractères distinctifs, de l'homogénéité et de la stabilité. 2000. UPOV/TG/81/6 Helianthus annuus 34: 2-34. 
